\title{
Crisis Management Mode of American College Students and Its Enlightenment on China
}

\author{
Sha Liu \\ Institute of mechanical and auto engineering, Changzhou Vocational Institute of Engineering, \\ Changzhou Jiangsu, 213164, China
}

Keywords: Crisis management, College, Management mode.

\begin{abstract}
This paper analyzes crisis management mode of American campus and its enlightenment on China in detail. The author firstly discusses the causes and features of college campus crisis, then starts from crisis management mode of American campus and discusses management procedure of American college campus and social support of crisis management of American college campus. On this basis, the author considers its enlightenment on China mainly includes strong awareness of unexpected development, eliminating crisis in the bud, establishing college campus crisis management system and improving crisis management idea dominated by legal system and prevention.
\end{abstract}

\section{Introduction}

As mass education moves towards elite education in China, colleges become the place where talents converge. Meanwhile, they also become the place where good and evil people mix. As multiple new media appear, the range of information spreading increases continuously. Information closure has become empty talk. In the face of such increasingly complex environment, the occurrence frequency of crises is on the rise. Crisis handling and management also become an important standard to test modern colleges and leadership skills of colleges. In this aspect, America is a leader. Especially after " 911 ”, all walks of life in American society greatly improve safety protection awareness, and issue laws, regulations and guidelines. This is beneficial to crisis management of Chinese colleges.

\section{Features and causes of college campus crisis}

Crisis management scholar Rosenthal indicates that crisis refers to the threat of violating basic value and behavior norms of social system in a social system. Besides, such threat has high uncertainty. The event must be properly handled through relevant decisions. College campus crisis refers to the event which seriously interferes in normal teaching order of colleges due to the reasons of colleges or external causes. Such events will cause life and properties of teachers and students are threatened, or result in the loss of public properties. In addition, such events are emergencies that campus human resource cannot be immediately solved.

\section{Features of college campus crisis.}

Generally, college campus crisis includes the most significant features of some critical incidents, i.e. violent injury, accidental injury, mass disturbance, epidemics and social crisis etc. Meanwhile, as people's ideology changes, college campus crisis also presents some new features. Firstly, as crisis generation mechanism expands increasingly, generation mechanism expansion is a new feature which forms with social development. Social development generates economic globalization. The range for college students to contact society is more extensive. Especially after network enters thousands of households, this feature is demonstrated. Besides, China is now in the social change period, external environment becomes increasingly complex. College reform deepens continuously. This further deepens such uncertain factor. Thus, new campus crisis occurs. Mass factor caused by campus crisis increases increasingly. Hence, generation mechanism of such crisis expands. Secondly, crisis nature is diversified. Crisis nature diversification is different due to the different colleges. This is not caused by different reasons. In essence, the society is in the change period under the 
background of economic globalization, and new campus crisis events occur, including emergencies caused by human factors such as demonstration and class boycott. Meanwhile, $d$ new campus crisis events also include emergencies caused by non-human factors such as natural disaster. Finally, the frequency of crisis outbreak also rises, which is an inevitable problem for open college running, such as critical incident which occurs due to intrusion of persons outside the college. In addition, there are also emergencies caused by unusual psychological and spiritual diseases, such as spiritual depression, psychological problem and personality disorder. All these result in the rise in the frequency of crisis outbreak.

\section{Reasons for college campus crisis.}

There are many reasons for the outbreak of college campus crisis, but the author considers that the analysis can be carried out from subjective and objective aspects. The subjective cause is the cause of college students. Their psychology is not completely mature, and they may be easily aroused. This will give rise to college campus crisis event very easily. These consciousnesses are mainly reflected in immature ideology and hidden danger of character. Thus, their self-awareness and protection awareness are weak. Besides, their experience in handling things is insufficient, which also results in insufficient self-protection and coping ability as well as college campus crisis. The objective causes mainly include the reasons of society and colleges. Social causes include the following: criminal offenders enter the campus and passive influence of network gradually appears. All these will result in the outbreak of crises. Campus management is also an important aspect. For example, ideological and political education, and comprehensive management measures cannot be implemented.

\section{Campus crisis management mode of American colleges}

Campus crisis management mode of American colleges has formed a unique system. The author thinks the mode covers two parts: college campus crisis management procedure, and social support of college campus crisis management.

\section{College campus crisis management procedure.}

US Department of Education issued and implemented Practical Data of Crisis Plan: College and Community Management Guide in 2003. This guide explicitly indicates four stages of crisis: incubation period, outbreak period, recovery period and reconstruction period. For the four stages of crisis, corresponding four crisis management links appear: crisis prevention, crisis preparation, crisis response and recovery after crisis.

Crisis prevention covers environmental examination, enhancement of safety facilities, supervision of college students' actions, psychological intervention in college students, monitoring and response of campus police. American police campus plays the greatest role. They mainly implement law enforcement function, safeguard personal property and life safety of teachers and students. They also have management function, i.e. safety management function of maintaining campus. College students' affairs office also plays an important role. They supervise and manage students from ideological and psychological aspects. The personnel cover psychologists, psychiatrists and crisis management personnel etc.

Crisis preparation covers crisis plan design and preparation, crisis plan drill and crisis material reserve etc. Crisis plan mainly involves explanation and description of crisis types and crisis handling methods. Human life should be put in the first place in the crisis plan. Meanwhile, crisis plan includes contact information. Crisis plan drill makes everyone familiar with the contingency plan and respective tasks. Once the crisis happens, the plan will be activated automatically.

The response to crisis occurrence refers to the functions of each department and link of crisis management after the plan activated automatically, such as crisis evaluation, closure or evacuation of colleges or how to cope with media personnel as well as timely update of website information.

Final recovery means crisis plan has been completed. It is necessary to optimize emergence event plan, reduce the loss caused by the crisis and properly handle corresponding work.

\section{Social support of college campus crisis management.}

Campus crisis management of American colleges has been resorting to public management. Regardless of public colleges and private colleges, campus belongs to public field. Hence, when 
America handles college campus crisis, it attaches great importance to management work and regards it as a constituent part of crisis management. Social support includes federal support and state-level support, promotes and improves relevant work of college crisis management from social level.

Federal Emergency Management Agency mainly prevents major disasters and emergencies which happen in U.S. If major disasters or emergencies happen, Federal Emergency Management Agency will formulate corresponding measures and solutions. Campus crisis management of American colleges has been a long history. Federal Emergency Management Agency has a long cooperation history with education sector in each state. For example, Gun-Free Schools Act (GSFA) was enacted in 1994. Besides, Federal Education Bureau required each state to issue Campus Environment Improvement Act (IASA). If it is not issued in 1995, education fund qualification will be cancelled. In 1995, the acts which could met GSFA appeared in each state. Then, Practical Data of Crisis Plan: College and Community Management Guide was implemented in 2003. it describes the types of various crises, and indicates the methods and measures to prevent crises.

Actually, after 911 event, the government planned college crisis monitoring more strictly. US Department of Education issued 2002-2007 Strategic Planning and especially stressed establishment of safety goal of colleges. The content covers enhancement of students' character education, civic awareness and patriotism education. All these are reflected in their courses, teaching and negotiation.

In fact, except education department, other departments also pay attention to college crisis management and issue relevant acts. For instance, Immigration Office restricted survey of Beijing students studying in America and established students' personal information bank. The government can look over information of overseas students through taking the data of information bank.

\section{Enlightenment of American college campus crisis management mode on China}

The concept of "harmonious society" has enjoyed popular support. As a part of society, harmonious campus is inevitable. But in such new situation, construction of harmonious campus encounters uncertain factors. In such case, it is required to eliminate campus crisis in order to construct a harmonious campus. Elimination of campus crisis is the minimum appeal of constructing a harmonious campus.

\section{bud.}

Own strong awareness of unexpected development and eliminate crisis awareness in the

Chinese nation has very strong awareness of unexpected development all the time. The occurrence of crisis is not baseless. So, the most important thing is to take precautions and prepare for the danger in times of safety. In this aspect, the author considers colleges should have crisis awareness. The terrible nature of college campus crisis lies in its emergency. But if colleges have crisis awareness and pay close attention to every action of college students, such feeling can be strangled in the cradle. Hence, college managers must have crisis awareness, such as college development crisis awareness, individual interest crisis awareness and student interest crisis awareness. They should motivate crisis awareness with the awareness of unexpected development and generates striving awareness through crisis awareness so that the leaders can lead all members to struggle. Secondly, colleges should establish crisis concept, must regard crisis awareness as an idea and make it go deep into the mind of each college worker. Colleges should not just have sober consciousness for crisis, but also make preparations in actions and prepare to struggle against the crisis all the time. Managers and teaching staffs should train teachers and students. They should not deem the crisis as a terrible thing, college employees should have good ability to relieve the crisis and especially well utilize modern science and technology to rethink and investigate the crisis.

\section{Establish college campus crisis management system.}

College campus crisis management is not just a problem of colleges, but also a systematical job. We must establish such a system in order to avoid campus crisis. In campus crisis management of Chinese colleges, there must be a complete management system. A sound management organ should be set up to formulate crisis management plan. Colleges should be able to identify the crisis. When a crisis happens, colleges should be bale to carry out a series of plans and emergency measures so as to reduce the crisis to the minimum. After the crisis is over, normal teaching order should be recovered 
as soon as possible. Besides, the management system should be properly evaluated to make such crisis management system more sound and college crisis management system become a closed-loop interactive control system with both-way information flow, and ensure construction of a harmonious campus.

\section{To improve crisis management concept dominated be legal system and prevention.}

In the development process of American college crisis management system, we can see it has a sound legal system. From Gun-Free Schools Act, Law of Campus, Social Drug Control and Safety, Campus Environment Improvement Act and Practical Data of Crisis Plan: College and Community Management Guide to Federal Contingency Plan, they are detailed coping acts with explicit goal and responsibility. Thus, China should refer to American college crisis management system.

Prevention is most important. Realizing the crisis and strangling it in the cradle is the best crisis handling scheme. Colleges should prevent various campus crises, face them with positive attitude and propose rational strategies so as to better handle campus crises.

\section{Acknowledgments}

This paper is the research result of 2014 special topic guidance project of counselor's work seminar in colleges of Jiangsu Province, Project No.: 14FYHLX31.

\section{References}

[1] Sun Hua, American college campus crisis management mode and its enlightenment, Research in Higher Education of Engineering, 2007 (3).

[2] Li Xiaoming, College campus crisis management idea and value realization, Education and Vocation, 2012.3

[3] Wu Jinhui, On Chinese college campus crisis management, Modern Enterprise Education, 2006 (11).

[4] Ai Fengyue, Study on college campus crisis management based on crisis management theory, Master’s thesis in Dalian University of Technology, 2008.6.

[5] Geng Yina, Construction and improvement of campus crisis management, Research of Modern Young People, 2008.3.

[6] Wei Zonglei, American crisis management mechanism, International Information, 2002 (11).

[7] Luo Liming, Liu Yiguo, College crisis management: cognition reconstruction and value selection, Journal of Inner Mongolia Normal University, 2005 (7) . 